$1-1-1972$

\title{
Studies on the maturity and storage behavior of red delicious budsports
}

L. Morris Ingle

Follow this and additional works at: https://researchrepository.wvu.edu/ wv_agricultural_and_forestry_experiment_station_bulletins

\section{Digital Commons Citation}

Ingle, L. Morris, "Studies on the maturity and storage behavior of red delicious budsports" (1972). West Virginia Agricultural and Forestry Experiment Station Bulletins. 609T.

https://researchrepository.wvu.edu/wv_agricultural_and_forestry_experiment_station_bulletins/705 @ WVU. It has been accepted for inclusion in West Virginia Agricultural and Forestry Experiment Station Bulletins by an authorized administrator of The Research Repository @WVU. For more information, please contact ian.harmon@mail.wvu.edu. 


\section{studies}

on the maturity

and storage behavior of red delic
budsports

Bulletin 609T

August 1972

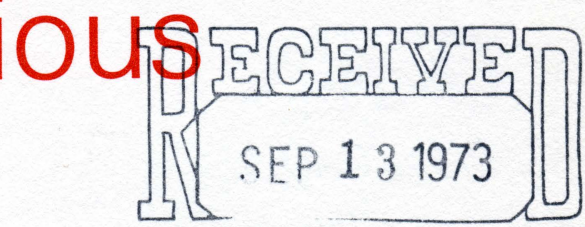

AG. ENGR. LIBRARY

WEST VIRGINIA UNIVERSITY

west virginia university agricultural experiment station

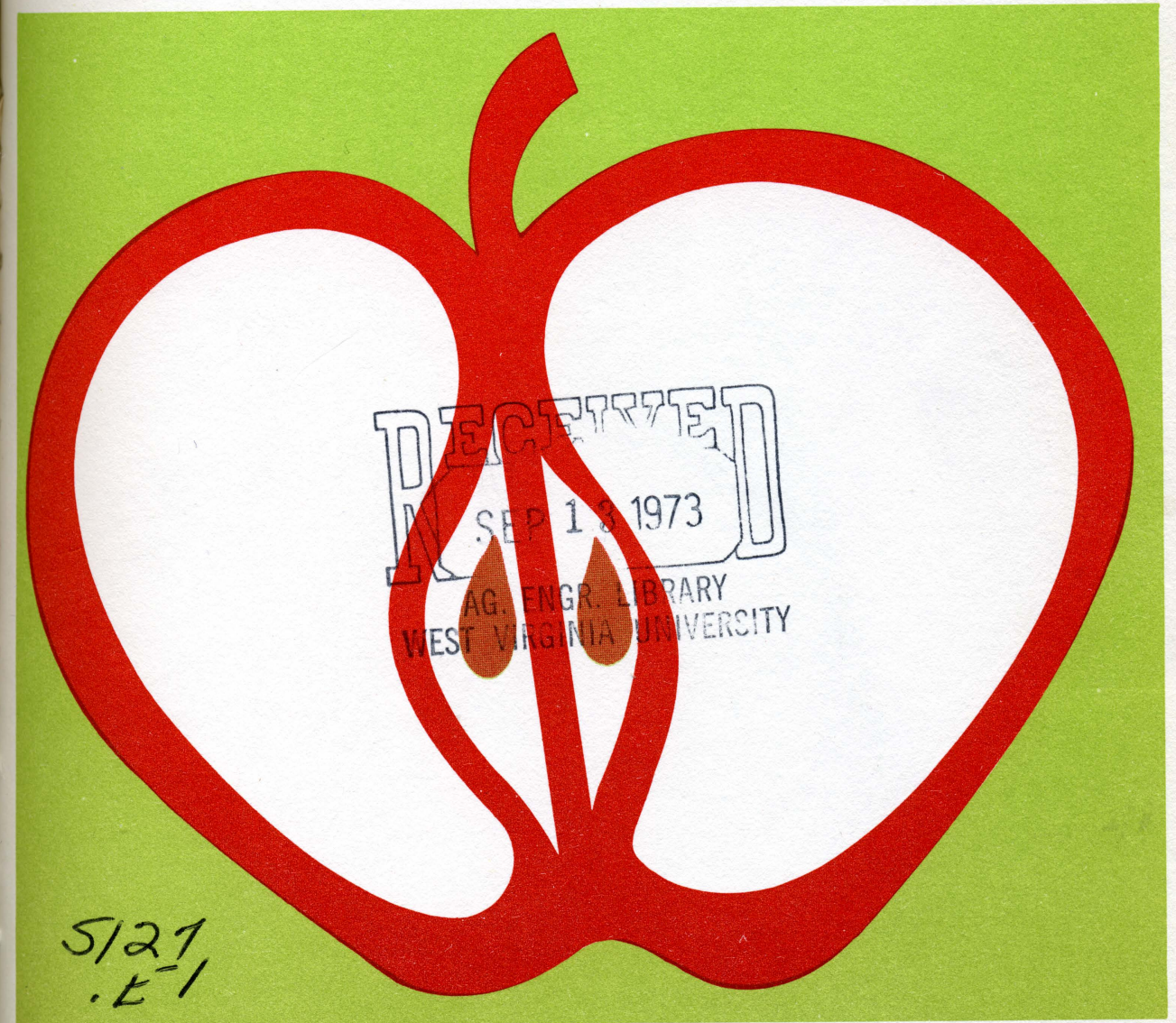


[Blank Page in Original Bulletin] 


\title{
Studies on the Maturity and Storage Behavior of Red Delicious Budsports
}

\author{
Morris Ingle
}

\section{CONCLUSIONS}

The principal findings and conclusions of these studies are:

1. Strains of Red Delicious apples mature at different times. Soluble solids adequately measure these differences and allow strains to be placed in a harvesting sequence.

2. A soluble solid concentration of 10.5 per cent indicates that fruit quality will be satisfactory after long-term storage. 


\section{THE AUTHOR}

Morris Ingle is Horticulturist, West Virginia Agricultural Experiment Station.

\section{ACKNOWLEDGMENTS}

The advice and assistance of Dr. E. C. Townsend on statistical procedures and analyses are gratefully acknowledged. Professor Edwin Gould, formerly in charge of the Kearneysville Substation, provided a great deal of experimental fruit and assistance. Mr. H. W. Miller, Jr., Consolidated Orchards, Inc., Paw Paw, West Virginia, and Mr. John Porterfield, Martinsburg, West Virginia, provided generous supplies of fruit for this study.

West Virginia University Agricultural Experiment Station College of Agriculture and Forestry

R. S. Dunbar, Jr., Director Morgantown 


\section{Studies on the Maturity and Storage Behavior of Red Delicious Budsports}

\section{MORRIS INGLE}

Q INCE the Delicious apple cultivar was introduced in 1881 , it has steadily increased in economic importance (17). The characteristics that contribute most to its acceptance are red color, unique shape, and long storage potential. Before 1939, 10.9 per cent of all apple trees set in West Virginia were some type of Delicious; in the next 25-year interval the proportion increased to 19.8 per cent. Production increased from 16.9 per cent of the United States commercial crop in 1942 to 30.4 per cent in 1969 (17). Delicious production in West Virginia is following the same trend, having increased from 10 per cent of the commercial crop in 1942 to 19.1 per cent in 1969. With increased plantings of Delicious trees, West Virginia production should continue to increase beyond the 51.7 million pounds reported for 1969 (21).

After the introduction of the original Delicious, a large number of mutants or "sports" were discovered. By 1960, Blodgett and Aichele were able to list 69 variants, strains or budsports that had received names and appeared to have had distinct origins (4). Since then about 30 new strains have been listed by Brooks and Olmo (5). These new strains appear to arise by somatic mutations in buds, giving rise to a limb or occasionally an entire tree with distinctive characteristics. Since apples are propagated vegetatively, desirable new strains can be perpetuated. The characteristics which have attracted most attention commercially relate to color, quantity, quality, pattern (striped versus solid), and rate of development. Attention also has been given to tree type-that is, the standard, conventional growth pattern as compared to the so-called spur-type tree, characterized by relatively restricted terminal growth and prolific production of first-bearing shoots or spurs along the larger branches.

There is limited evidence to suggest that there are some physiological differences between the Delicious strains in addition to the visual color variations. Dayton (7) found that 37 Delicious strains could be grouped into seven classes on the basis of distribution of pigment, vacuoles in the epidermis, tree type, and fruit color pattern. While simple mutations on the outer layer of the shoot apex would account for some differences in color pattern and intensity in strains with standard tree form, the relation of the spur tree form to color pattern suggests more complex genetic modifications. If the strains do have several genetic differences, it would be reasonable to expect that there may be differences in the physiology of the fruit. 
Lord and Southwick found that "the incidence of water core at harvest and development of internal breakdown and scald after storage was greater in Richared than Starking Delicious apples in each of 3 years" (12). As harvest was delayed, water core at harvest and internal breakdown after storage became more severe and scald after storage became less severe. Ingle (10) and others have reported that scald is less severe on later-harvested or more mature fruits. One interpretation of Lord and Southwick's data is that Richared develops more rapidly than Starking. Brown et al. (6) found that the peaks in production of ethylene and other volatiles differed in time for the Royal Red and Starkrimson strains. Respiration data supported the conclusion that Royal Red matures earlier than Starkrimson.

If it is true that strains of Delicious develop at different rates and reach maturity at different times, it may be possible to plant several strains that will spread harvesting over a period of several weeks rather than the 7-10 days during which most apple cultivars are at optimum maturity. This concept would apply to existing plantings that include several Delicious budsports, as well as projected plantings. Efficient management (harvesting, packing, and storing) of Delicious could be substantially improved by a reliable and practical method of estimating maturity, coupled with knowledge of how the several cultivars behave in storage.

\section{Objective}

The primary objective of these studies was to determine if there were differences in the rate of maturation (date of maturity, optimum harvest date) and storage behavior of several strains or budsports of the Delicious cultivar and if there was a simple method of estimating the proper time to harvest. To be of maximum utility, estimation of maturity should be based on some objective measurement to minimize variation between individuals.

\section{Literature}

The several indexes of maturity or methods of estimating when to harvest apples that have been considered to have some practical value include fruit firmness, ease of separation, surface color, ground color, soluble solids, days from full bloom, calendar date, and respiration rate (18). Magness et al. (15) concluded that firmness, as measured by the Magness-Taylor pressure tester, was an excellent index for Delicious in determining the picking condition in the Pacific Northwest and Central Atlantic apple growing regions. Sixteen to eighteen pounds was considered to be the best picking range; however, an examination of their actual measurements shows a good deal of variation between locations and years. Only two years' data were provided. In one year there was softening in the month prior to the "optimum packing date" and in the other no such trend was apparent (15).

Smock (18) found the firmness of Mclntosh apples to be too variable to be 
of use as a maturity index. Magness et al. (14) were probably more correct when they suggested that firmness at harvest can be used as a guide to how the fruit will behave in storage. Lord and Southwick observed consistent declines in firmness of Richared and Starking between September 28-29 and October 20-24 in their three-year study; however, there was a good deal of variation and little value as a maturity index could be found (12).

Development of red surface color is obviously important since this determines grade and influences the marketability of a crop; however, red color is controlled by a number of environmental, nutritional, and genetic factors so that at best it is a very crude index of maturity (18). Part of the surface of many apple cultivars is not red. This green (and later yellow) portion is sometimes called the unblushed surface, or ground color. The change from green to yellow has often been considered as a good maturity index for many apple cultivars (18). This change is also controlled by environmental factors and may vary with the length of the growing season (14). Used with colored guide cards, ground color change can be fairly well quantified. This method cannot be applied to many of the Delicious budsports because they lack an unblushed surface and changes in chlorophyll can be observed only by pigment extraction or complex spectophotometric methods.

One of the most appealing indexes of maturity because of its simplicity is "days from full bloom." For the past several years, it has been recommended that Delicious be harvested 150-155 days after full bloom (1). Magness et al. placed the optimum harvest date from 137 days at East Lansing, Michigan, to 153 days at Wooster, Ohio, although there was considerable variations at some locations between the two years of their study. At Rosslyn, Virginia, the nearest station to West Virginia, the optimum harvest dates occurred 138-139 days after full bloom (15).

In another paper, Magness et al. generalized that Delicious should be harvested after about 145 days (14). Using ground color as the indication of maturity, Tukey concluded that Delicious should be harvested after 129-134 days at Geneva, New York (19). Ellendwood suggested an interval of 153 days in Ohio (8). Utilizing 114 sets of data from eight locations throughout North America, Blandpied showed that Delicious matures between 135 and 155 days after full bloom (2). Short growing seasons were correlated with late bloom dates; there was no correlation between accumulated heat units and harvest date. It must be noted that there was no consistent definition of maturity. With the exception of the Blandpied report, it can be assumed that the original Delicious strain was involved in all the other studies since they were conducted before extensive production of any of the sports could have commenced.

Kidd and West were the first workers to suggest that the optimum harvest data could be correlated with the onset of the climacteric rise (11). Smock concluded that the respiration pattern might be a good index for experimental 
studies with Mclntosh apples but was of little practical value (18). In a study extending over eight years, Blandpied (3) measured the respiration of samples of Delicious, Red Delicious, McIntosh, and Cortland fruits harvested at three- to five-day intervals over a period of nearly one month. Similar samples harvested on the same dates were evaluated for quality (firmness, eating quality, appearance) after four to five months of storage at $0^{\circ} \mathrm{C}$. Optimum harvest date, derived from quality after storage, was not associated with any point on the climacteric curve.

It is generally assumed that sugar content measured as soluble solids increases just prior to maturity and during ripening, although Magness et al. (14) believed that sugar content was affected by too many factors to be a reliable index of quality. Smock also believed that soluble solids varied too much from year to year to be of value as a maturity index (18). Conversations with horticulturists suggested that this method might be of value for estimating Delicious maturity and distinguishing between strains, although there is essentially no published data on this parameter. Moshsennin et al. (16) observed that sugar content (soluble solids) increased steadily between 110 and 160 days after full bloom. Soluble solids were 11.3 per cent $( \pm 1.5$ per cent) 143 days after full bloom in 1961 and 14.3 per cent $( \pm 2.1$ per cent) 149 days after full bloom in 1962. No climatic data for the two years were given to account for the variations in soluble solids.

\section{Methods}

The location and characteristics of the trees from which fruit was obtained will be described as each year's data are discussed. As a general method, fruit was collected from all parts of the selected trees and placed in marked containers. Standard one-bushel wooden field boxes were used except in the 1964-65 work. The samples were taken to the laboratory on the day of collection and stored overnight at room temperature $\left(22^{\circ} \mathrm{C}\right)$. Estimates of firmness and soluble solids were made the following day. One-quarter of each tested fruit was placed in a plastic bag and frozen rapidly for later determination of titratable acidity and $\mathrm{pH}$. In most cases, 60-100 fruits were collected, 20 randomly selected fruits tested the following day at harvest, and the remainder placed in storage at $0-2^{0}$ C. Fruits typical for color, shape and within a half-inch diameter range were used. Size varied between cultivars and replications so that not all samples were exactly the same; all reasonable effort was made to reduce size variability.

Firmness was estimated on opposite pared sides with a Magness-Taylor pressure tester (N. Balluaf Co., Inc.) clamped horizontally to a table top. The 7/16-inch tip was inserted $1 / 2$ inch. Soluble solids were estimated with a Zeiss or American Optical hand-held refractometer graduated with the international sucrose scale on a sample of juice expressed from an $8 \mathrm{~mm}$ diameter cylindrical core with a hand press. Acidity was measured by titration to $\mathrm{pH} 8.0$ with $0.1 \mathrm{~N}$ 
$\mathrm{NaOH}$ of a $10 \mathrm{ml}$ aliquot of juice prepared from a composite of the quarters of all fruits in a sample. The juice was prepared with a motorized food grinder or Waring VJ-1 Juicer and forced through eight layers of cheese cloth. Tissue was maintained at $-20^{\circ} \mathrm{C}$ until extraction and titration could be performed.

\section{Results}

The possibility of variation in the rate of maturation between strains or budsports was first proposed in 1964. Since little information was available, it was decided to survey a large number of accessions being evaluated for other horticultural characteristics at the Kearneysville Substation of the West Virginia Agricultural Experiment Station. In "Block X" Stayman trees on seedling root stocks set $20 \mathrm{ft}$. $\times 20 \mathrm{ft}$. in 1951 had been topworked with Delicious buds in 1958. Two 25 fruit samples were collected from one of the trees in the first replicate. Trees were chosen for uniformity of size and fruit load. In "Block C" Malling VII root stocks were budded with Red Delicious strains and set in place in 1958. Most of the budding was done in 1957. A planting distance of $30 \mathrm{ft} . x$ $20 \mathrm{ft}$. was used. By 1964, the trees had an average height of approximately seven feet. Twenty-five fruits were collected from each of the four trees in the first replicate.

Table 1 shows the firmness and soluble solids averages for the $\mathbf{5 0}$ fruits from the strains sampled in Block $X$. Since there was no proper replication, formal statistical analysis was not attempted; however, it is possible to discern some variation between the strains. On September 8, the mean firmness for all strains was 18.95. During the next nine days, the average firmness decreased to 18.54 . A few strains showed a slight increase in firmness during that interval, but probably none of the changes had any meaning. The average firmness for all strains increased by two pounds between September 17 and 26. This change seems contrary to the commonly accepted opinion that firmness decreases as fruit matures. In fact this increase during the latter stages of development was observed by Magness et al. in 1923 and 1924. Statistical analysis was precluded by the lack of replication but some strains appear to be distinctly firmer than others. Focusing attention on the September 17 collection before the increase in firmness Earli-Red, Ryan Red, Gilbert, Riggs Spur, and Myrtle appear to be examples of the firmer strains, while Red Queen, Houser, and Hardeman are softer.

Since fruits were collected from four trees of each strain in Block C, it was possible to perform an analysis of variance. In this block an increase in firmness occurred between the first collection on September 8 and the second collection on September 17. No difference in firmness between strains could be detected statistically. However, some of the differences in Table 2 seem large enough to suggest that not all Red Delicious strains are the same with respect to firmness during a period $135-150$ days after full bloom, the general season of Delicious 
TABLE 1

Firmness and soluble solids of 32 Delicious strains, Block $X$, Kearneysville Substation, 1964. Means of 50 fruits.

\begin{tabular}{|c|c|c|c|c|c|c|}
\hline \multirow[b]{2}{*}{ Strain } & \multicolumn{6}{|c|}{$\begin{array}{cc}\text { Collection Date } \\
\end{array}$} \\
\hline & Sept. 8 & Sept. 17 & Sept. 26 & Sept. 8 & Sept. 17 & Sept. 26 \\
\hline & \multicolumn{3}{|c|}{ Firmness-Pounds } & \multicolumn{3}{|c|}{ Soluble Solids-Per cent } \\
\hline Red Queen & 17.7 & 17.1 & 20.4 & 12.50 & 12.50 & 13.12 \\
\hline Red Prince & 18.9 & 18.2 & 21.0 & 13.50 & 13.25 & 13.13 \\
\hline Royal Red & 19.5 & 18.2 & 20.1 & 11.75 & 12.75 & 13.75 \\
\hline Red King & 18.6 & 17.7 & 20.7 & 11.00 & 12.00 & 14.66 \\
\hline Starkrimson & 18.1 & 17.8 & 20.4 & 10.25 & 11.00 & 11.75 \\
\hline Earli-Red & 20.1 & 19.3 & 19.8 & 11.50 & 13.25 & 13.50 \\
\hline Chelan Red & 18.3 & 18.1 & 21.1 & 12.00 & 13.50 & 13.50 \\
\hline Ryan Red & 18.3 & 19.1 & 20.6 & 10.25 & 12.00 & 13.00 \\
\hline Harrold & & 18.4 & 20.6 & 10.75 & 12.75 & 14.00 \\
\hline Hi-Red & 18.4 & 19.0 & 20.1 & 10.75 & 13.00 & 12.25 \\
\hline Red Spur & 19.1 & 18.6 & 20.8 & 10.75 & 12.75 & 12.38 \\
\hline Twin Butte 1 & 19.9 & 19.0 & 20.5 & 10.75 & 12.75 & 13.75 \\
\hline Imperial & 19.0 & 19.3 & 20.2 & 10.88 & 11.75 & 14.25 \\
\hline Gilbert & 19.5 & 19.8 & 20.9 & 11.00 & 13.00 & 14.50 \\
\hline Jardine & 18.7 & 19.2 & 21.0 & & & \\
\hline Houser & 17.9 & 17.9 & 19.4 & 10.75 & 11.50 & 12.25 \\
\hline Hardeman & 18.2 & 17.4 & 20.1 & 10.50 & 13.00 & 14.25 \\
\hline Okanoma Red & 18.2 & 18.7 & 20.2 & 11.00 & 12.25 & 12.88 \\
\hline Riggs Spur & 17.9 & 19.7 & 20.4 & 11.25 & 12.00 & 13.13 \\
\hline Rypczynski & 19.1 & 19.3 & 21.1 & 10.75 & 13.25 & 12.38 \\
\hline Topred & 18.3 & 18.8 & 21.6 & 11.00 & 12.75 & 12.13 \\
\hline Wellspur & 18.5 & 17.9 & 19.9 & 11.00 & 12.25 & 12.13 \\
\hline Wellspur No. 2 & 20.2 & 17.9 & 20.5 & 11.00 & 12.25 & 13.75 \\
\hline Hi-Early & 18.9 & 18.0 & 20.2 & 11.15 & 12.00 & 12.00 \\
\hline Worthen No. 1 & 20.7 & 18.7 & 21.6 & 9.75 & 12.50 & 14.38 \\
\hline Worthen No. 2 & 20.9 & 17.8 & 21.3 & 11.25 & 15.00 & 14.13 \\
\hline Heisey & 20.0 & 19.2 & 21.1 & & 13.00 & 15.25 \\
\hline Starking & 19.9 & 17.8 & 22.1 & 10.75 & 12.25 & 12.50 \\
\hline Skyline Supreme & 18.9 & 18.3 & 20.6 & 9.25 & 12.50 & 11.38 \\
\hline Vance & 18.5 & 19.1 & 19.7 & 10.75 & 11.50 & 12.75 \\
\hline Myrtle & 19.2 & 19.0 & 21.1 & 12.00 & 12.25 & 13.00 \\
\hline “Unknown" & & 20.7 & 19.8 & & & \\
\hline Richared & 18.0 & 16.9 & 18.5 & 10.25 & 9.75 & 11.75 \\
\hline Mean & 18.95 & 18.54 & 20.53 & 11.00 & 12.46 & 13.15 \\
\hline
\end{tabular}


TABLE 2

Firmness and soluble solids of 14 Delicious strains, Block C, Kearneysville, 1964.

\begin{tabular}{lccc|ccc}
\hline \hline & \multicolumn{6}{c}{ Collection Date } \\
\cline { 2 - 7 } Strain & Sept. 8 & Sept. 17 & Sept. 26 & Sept. 8 & Sept. 17 & Sept. 26 \\
\hline & \multicolumn{3}{c}{ Firmness-Pounds } & \multicolumn{4}{c}{ Soluble Solids-Per cent } \\
Red Queen & 15.5 & 16.2 & 13.5 & 11.33 & 12.63 & 11.75 \\
Red Prince & 14.7 & 17.8 & 14.6 & 10.83 & 13.13 & 12.33 \\
Royal Red & 15.3 & 17.4 & 14.9 & 10.88 & 12.38 & 11.63 \\
Red King & 15.7 & 16.7 & 15.4 & 11.00 & 12.00 & 12.88 \\
Starkrimson & 14.7 & 16.7 & 14.7 & 9.75 & 11.38 & 12.25 \\
Chelan Red & 15.9 & 14.9 & 15.2 & 10.63 & 12.00 & 12.50 \\
Ryan Red & 16.5 & 17.1 & 14.4 & 10.67 & 11.62 & 13.00 \\
Red Spur & 16.2 & 17.1 & 15.1 & 10.13 & 11.17 & 10.25 \\
Jardine & 15.7 & 16.9 & 15.0 & 10.83 & 12.67 & 14.50 \\
Houser & 16.0 & 14.5 & 15.4 & 10.13 & 11.83 & 11.38 \\
Rypczynski & 16.6 & 16.6 & 15.6 & 10.63 & 11.88 & 11.88 \\
Topred & 16.5 & 17.9 & 15.2 & 10.88 & 11.33 & 11.75 \\
Wellspur & 15.1 & 16.6 & 15.4 & 9.63 & 11.00 & 9.83 \\
Hi-Early & 15.1 & 16.9 & 15.8 & 10.50 & 12.50 & 11.50 \\
Mean & 15.7 & 16.7 & 15.0 & 10.56 & 11.97 & 11.96 \\
\hline
\end{tabular}

harvest. It was recognized that because of variations and changes from one harvest date to the next, it was unlikely that firmness would be a reliable indicator by itself of maturity or "time-to-harvest."

In 1964, the soluble solids or sucrose concentration generally showed an increase through the collection period and there was reasonable consistency between the two blocks. Some examples can be found of declines between the second and third collections. Declines in soluble solids were confined to strains with relatively high soluble solids at the first and second collections. Red Prince from both blocks was highest in soluble solids on September 8 and then showed a small decrease. The Red Queen from Block $\mathrm{C}$ behaved similarly. Assuming that soluble solids content is an indication of maturity, these measurements again suggest that Red Prince, Royal Red, Red Queen, Harrold, Hardeman, and Imperial develop ahead of other strains, such as Starking, Richared, and Starkrimson (Bisbee). Some strains with extreme values have not been measured in subsequent years because certain tree and fruit characteristics have eliminated them as acceptable strains in West Virginia. Ryan Red and Topred, two strains 
with good tree growth and fruit characteristics, seemed to be intermediate and to have changed slowly during the harvest season. While the differences between the strains could not be demonstrated statistically, they seemed large and consistent enough to continue investigation.

These studies were suspended for two years because spring frosts prevented normal fruit set and development. Then in 1967 six strains from Block $C_{\text {, }}$ Kearneysville, were compared. Table 3 shows that fruit firmness fluctuated most irregularly and no patterns could be discerned, although there was a significant difference between strains on the second collection date, September 19. The differences in soluble solids concentrations between strains and collection dates were small and not statistically significant even at the 90 per cent level but they did show consistent trends (Table 4). Furthermore, in terms of the relationship between strains, these data are quite consistent with those obtained in 1964.

TABLE 3

Pulp firmness of six strains of Red Delicious apples, Block C, Kearneysville, 1967.

\begin{tabular}{lcccc}
\hline \hline & \multicolumn{4}{c}{ Harvest Date } \\
\cline { 2 - 5 } Strains & Sept. 15 & Sept. 19 & Sept. 21 & Sept. 26 \\
\hline Red Queen & 19.1 & 21.1 & 20.4 & 20.1 \\
Royal Red & 21.5 & 21.6 & 21.0 & 20.5 \\
Bisbee & 20.4 & 21.8 & 21.8 & 21.1 \\
Ryan Red & 18.2 & 23.2 & 22.8 & 20.4 \\
Houser & 21.7 & 20.8 & 21.2 & 21.4 \\
Richared & 22.3 & 20.2 & 21.0 & 21.8 \\
\hline
\end{tabular}

TABLE 4

Soluble solids of six strains of Red Delicious apples, Block C, Kearneysville, 1967.

\begin{tabular}{lcccc}
\hline \hline & \multicolumn{4}{c}{ Harvest Date } \\
\cline { 2 - 5 } Strains & Sept. 15 & Sept. 19 & Sept. 21 & Sept. 26 \\
\hline Red Queen & 10.0 & 10.8 & 10.7 & 11.0 \\
Royal Red & 9.7 & 9.9 & 10.4 & 10.2 \\
Bisbee & 8.5 & 9.3 & 9.0 & 10.0 \\
Ryan Red & 9.6 & 10.0 & 10.0 & 10.4 \\
Houser & 10.5 & 10.1 & 10.7 & 11.0 \\
Richared & 8.8 & 8.5 & 8.9 & 9.2 \\
\hline
\end{tabular}


Richared, one of the earlier sports of Delicious, was relatively low in soluble solids on all collection dates. Houser, a recent (1956) sport of Starking, with intense red color and blush pattern, was high in soluble solids throughout the experimental collection period. Red Queen, another Starking budsport with moderately high color but in a stripe pattern, was at nearly the same level of soluble solids. Starkrimson (Bisbee), a spur-type mutant of Starking which originated at the same time as Red Queen, was much lower than Houser or Red Queen on all collection dates. Initially, it appeared similar to Richared but increased more rapidly, particularly during the latter part of September. Royal Red, a 1958 mutant of Richared and Ryan Red, a 1953 mutant of Starking, appeared very similar in soluble solids.

Table $\mathbf{5}$ is included as an example of titratable data as it was collected over several years. No well-defined differences between strains or trends with time can be observed. The soluble solids: titratable acidity ratio did not appear to provide any more information than soluble solids alone.

Because the 1968 Delicious crop at Kearneysville was largely eliminated by spring frost, fruits were collected from two commercial orchards. One was the Martin's Mountain Orchard of Consolidated Orchards, Paw Paw, W. Va. The elevation is approximately $\mathbf{4 0 0}$ feet and the soil is a thin loam underlain by shale. The root stock for all strains except Richared was East Malling VII. The Richared trees were on seedling root stocks. All five strains were growing in contiguous areas but not in the same blocks. The Red Prince and Red Queen were planted in adjacent rows in the same block. These trees were 10 years old in 1968. Since it did not appear that a single tree would provide sufficient fruit, a pair of adjacent similar trees was used as a replication. A pair of trees of the other strain in the adjacent row was similarly selected. Pairs of trees were

\section{TABLE 5}

Titratable acidity of juice of six strains of Red Delicious apples, Block C, Kearneysville, 1967.

\begin{tabular}{lcccc}
\hline \hline \multirow{2}{*}{ Strain } & \multicolumn{4}{c}{ Harvest Date } \\
\cline { 2 - 5 } & Sept. 15 & Sept. 19 & Sept. 21 & Sept. 26 \\
\hline \multirow{4}{*}{ Red Queen } & \multicolumn{4}{c}{ Meq/ml x $10^{2}$} \\
Royal Red & 4.94 & 4.30 & 3.11 & 3.74 \\
Bisbee & 4.74 & 4.59 & 2.79 & 3.76 \\
Ryan Red & 3.75 & 4.36 & 3.11 & 2.90 \\
Houser & 5.05 & 4.34 & 3.08 & 3.33 \\
Richared & 4.45 & 4.66 & 2.91 & 4.18 \\
& 5.25 & 5.05 & 3.01 & 3.87 \\
\hline
\end{tabular}


selected in Miller Spur ( 8 years old), Starkrimson (10 years old), and Richared (12 years old) blocks. The fruits collected from each tree in a pair were placed in separate containers and equal numbers composited into a single sample for testing and storage.

The other source of fruit in 1968 was the Marlowe Orchard of Centennial Orchards, Inc., at an elevation of $\mathbf{5 0 0}$ feet. The soil is a Hagerstown loam. All strains were 10 years old growing on seedling root stocks; hence, this block will be referred to as the "standard block." All strains except Starkrimson were in the same block. Each strain was planted with trees in alternate rows. Four trees of equal size and fruit load from along one side of the block were selected for sampling. The Starkrimson trees were immediately across a small orchard road. Trees from the second and third rows were used to avoid border effects.

Firmness was not measured at harvest because the tester disfunctioned during the testing of the first harvest and could not be replaced before the end of the collection period.

Table 6 shows the soluble solids on four collection dates from the Malling VII block and Table 9 three dates from the standard block. (There was insufficient fruit on some trees for a fourth collection.) In both blocks there were significant differences between strains, at least on some dates. As noted in previous years, Richared and Starkrimson were relatively low in soluble solids while Red Prince and Red Queen were higher. The position of one strain relative to another was not exactly the same in both blocks, but the same general pattern was obvious. Prior work had suggested that Houser was a strain high in soluble solids, particularly on early harvest dates. The Houser from the standard block in 1968 was intermediate in soluble solids although not statistically different from

\section{TABLE 6}

Soluble solids of five Delicious strains at harvest, Malling VIII Block, Martin's Mountain, 1968.

\begin{tabular}{lcccc}
\hline \hline \multirow{2}{*}{ Strain } & \multicolumn{4}{c}{ Collection Date } \\
\cline { 2 - 5 } & Sept. 10 & Sept. 17 & Sept. 24 & Oct. 1 \\
\hline Red Prince & $10.40 \mathrm{a}^{1}$ & $10.77 \mathrm{a}$ & $11.53 \mathrm{a}$ & $11.99 \mathrm{a}$ \\
Red Queen & $10.25 \mathrm{ab}$ & $10.52 \mathrm{a}$ & $11.54 \mathrm{ab}$ & $12.47 \mathrm{a}$ \\
Miller Spur & $10.12 \mathrm{ab}$ & $11.10 \mathrm{a}$ & $11.42 \mathrm{ab}$ & $12.52 \mathrm{a}$ \\
Starkrimson & $9.19 \mathrm{bc}$ & $9.05 \mathrm{~b}$ & $9.55 \mathrm{c}$ & $10.90 \mathrm{ab}$ \\
Richared & $8.45 \mathrm{c}$ & $9.00 \mathrm{~b}$ & $9.13 \mathrm{c}$ & $10.20 \mathrm{~b}$ \\
\hline
\end{tabular}

${ }^{1}$ Means followed by the same letter are not significantly different at the 5 per cent confidence level according to Duncan's New Multiple Range Test. 
the other four strains. Miller Spur was another strain that appeared intermediate. It should also be observed that differences between strains detected at the earlier harvests largely disappeared in two or three weeks. However, in the Malling VII block Richared was lower in soluble solids than Red Prince, Red Queen, and Miller Spur.

After storage for 120 days, some differences in behavior were observed. While most of these were not statistically significant, they are probably of practical meaning. After storage Richared and Starking were always firmer than the other strains (Table 7). This was particularly true of fruit from the later collections. Lack of firmness data at harvest makes it impossible to say how much a strain softened during storage, but it is clear that some strains do soften more than others and that this softening is influenced by harvest date. This problem will be treated further in the Discussion Section of this bulletin.

Physiological or superficial scald was severe on fruit from both blocks in 1968 (Table 8). All strains from the standard block were about equally affected with no statistically significant differences. The trend was for scald after storage to be less prevalant as harvest was delayed. In the Malling VII block scald was more severe on the early collections of Miller Spur than on the other strains. The increased severity of scald on the fourth collection of Red Prince, Red Queen, and Starkrimson was contrary to previous experience and is difficult to explain.

In 1969, there was a good crop of Delicious in Block $X$ at Kearneysville. The eight strains selected for study either were known to have been planted to a considerable extent commercially or to have shown sufficient potential to be recommended for commercial planting. Block $X$ contains four replications of each Delicious strain with each replication containing one to four trees. Fruit

\section{TABLE 7}

Firmness of five Delicious strains after 120 days storage at $0^{\circ} \mathrm{C}$

and 7 days at $20^{\circ} \mathrm{C}$, Malling VII Block, Martin's Mountain, 1968.

\begin{tabular}{lllll}
\hline \hline & \multicolumn{4}{c}{ Collection Date } \\
\cline { 2 - 5 } Strain & Sept. 10 & Sept. 17 & Sept. 24 & Oct. 1 \\
\hline & & \multicolumn{3}{c}{ Pounds } \\
Richared & $13.7 \mathrm{a}^{1}$ & $14.1 \mathrm{a}$ & $13.4 \mathrm{a}$ & $11.8 \mathrm{a}$ \\
Miller Spur & $13.4 \mathrm{ab}$ & $13.6 \mathrm{ab}$ & $13.1 \mathrm{ab}$ & $11.9 \mathrm{a}$ \\
Starkrimson & $12.9 \mathrm{bc}$ & $14.5 \mathrm{abc}$ & $12.0 \mathrm{bc}$ & $11.2 \mathrm{a}$ \\
Red Prince & $12.5 \mathrm{c}$ & $13.3 \mathrm{abc}$ & $12.0 \mathrm{bc}$ & $11.1 \mathrm{ab}$ \\
Red Queen & $12.4 \mathrm{c}$ & $12.6 \mathrm{c}$ & $11.6 \mathrm{c}$ & $9.9 \mathrm{~b}$ \\
\hline
\end{tabular}

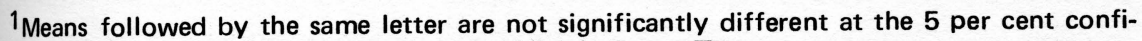
dence level according to Duncan's New Multiple Range Test. 


\section{TABLE 8}

Storage Scald on five Delicious strains after 120 days storage at $0^{\circ} \mathrm{C}$, and 7 days at $20^{\circ} \mathrm{C}$, Malling VII Block, Martin's Mountain, 1968.

\begin{tabular}{|c|c|c|c|c|}
\hline \multirow[b]{2}{*}{ Strain } & \multicolumn{4}{|c|}{ Collection Date } \\
\hline & Sept. 10 & Sept. 17 & Sept. 24 & Oct. 1 \\
\hline & \multicolumn{4}{|c|}{ Per cent Affected } \\
\hline Miller Spur & $95.0 \mathrm{a}$ & $10.0 \mathrm{a}$ & $95.7 \mathrm{a}$ & $67.9 a$ \\
\hline Red Prince & $87.5 a b$ & $65.5 b$ & $33.8 b$ & $68.9 a$ \\
\hline Red Queen & 81.0ab & $71.0 \mathrm{~b}$ & $21.6 b$ & $32.7 a$ \\
\hline Starkrimson & $77.2 \mathrm{~b}$ & $48.7 b$ & $23.7 b$ & $88.6 a$ \\
\hline Richared & $67.5 b$ & $69.1 b$ & $96.2 \mathrm{a}$ & $62.9 a$ \\
\hline
\end{tabular}

TABLE 9

Soluble solids of five Delicious strains at harvest, Standard Block, Centennial Orchards, 1968.

\begin{tabular}{lccc}
\hline \hline & \multicolumn{3}{c}{ Collection Date } \\
\cline { 2 - 4 } Strain & Sept. 12 & Sept. 19 & Sept. 26 \\
\hline & & Per cent & \\
Red Queen & $11.22 \mathrm{a}^{1}$ & $11.99 \mathrm{a}$ & $11.87 \mathrm{a}$ \\
Houser & $11.10 \mathrm{a}$ & $11.52 \mathrm{ab}$ & $11.16 \mathrm{a}$ \\
Red Prince & $10.47 \mathrm{ab}$ & $11.42 \mathrm{ab}$ & $12.27 \mathrm{a}$ \\
Ryan Red & $10.10 \mathrm{ab}$ & $11.02 \mathrm{~b}$ & $11.48 \mathrm{a}$ \\
Starkrimson & $9.65 \mathrm{~b}$ & $10.95 \mathrm{~b}$ & $11.50 \mathrm{a}$ \\
\hline
\end{tabular}

${ }^{1}$ Means followed by the same letter are not significantly different at the 5 per cent confidence level according to Duncan's New Multiple Range Test.

was collected from one tree in each of these replicates, the trees being selected for uniformity of size, growth habit, fruit load, and apparent fruit quality. Variation between replicates would not be unexpected since the total area involved 20 acres.

Table 13 shows some statistically significant differences in firmness between strains. As in previous years, there was a tendency toward an increase in firmness as collection or harvest was delayed, particularly between September 18 and 25 . 
TABLE 10

Firmness of five Delicious stains after 120 days storage at $0^{\circ} \mathrm{C}$ and 7 days at $20^{\circ} \mathrm{C}$, Standard Block, Centennial Orchards, 1968.

\begin{tabular}{llcl}
\hline \hline & \multicolumn{3}{c}{ Collection Date } \\
\cline { 2 - 4 } Strain & Sept. 12 & Sept. 19 & Sept. 26 \\
\hline & & Pounds & \\
Bisbee & $14.07 \mathrm{a}^{1}$ & $14.26 \mathrm{a}$ & $13.03 \mathrm{a}$ \\
Ryan Red & $12.69 \mathrm{a}$ & $12.90 \mathrm{~b}$ & $11.27 \mathrm{~b}$ \\
Red Prince & $13.08 \mathrm{a}$ & $13.33 \mathrm{ab}$ & $11.13 \mathrm{~b}$ \\
Houser & $12.50 \mathrm{a}$ & $12.95 \mathrm{~b}$ & $11.59 \mathrm{~b}$ \\
Red Queen & $12.52 \mathrm{a}$ & $12.93 \mathrm{~b}$ & $11.38 \mathrm{~b}$ \\
\hline
\end{tabular}

$1^{1}$ Means followed by the same letter are not significantly different at the $\mathbf{5}$ per cent confidence level according to Duncan's New Multiple Range Test.

\section{TABLE 11}

Storage Scald on five Delicious strains after 120 days storage at $0^{\circ} \mathrm{C}$ and 7 days at $20^{\circ} \mathrm{C}$, Standard Block, Centennial Orchards, 1968.

\begin{tabular}{lccc}
\hline \hline & \multicolumn{3}{c}{ Collection Date } \\
\cline { 2 - 4 } Strain & Sept. 12 & Sept. 19 & Sept. 26 \\
\hline & & Per cent & \\
Bisbee & $53.7 \mathrm{a}$ & $56.6 \mathrm{a}$ & $41.5 \mathrm{a}$ \\
Red Queen & $46.2 \mathrm{a}$ & $46.9 \mathrm{a}$ & $32.1 \mathrm{a}$ \\
Red Prince & $47.8 \mathrm{a}$ & $51.8 \mathrm{a}$ & $35.3 \mathrm{a}$ \\
Houser & $49.7 \mathrm{a}$ & $39.5 \mathrm{a}$ & $36.1 \mathrm{a}$ \\
Ryan Red & $44.69 \mathrm{a}$ & $39.3 \mathrm{a}$ & $30.6 \mathrm{a}$
\end{tabular}

${ }^{1}$ Means followed by the same letter are not significantly different at the 5 per cent confidence level according to Duncan's New Multiple Range Test. (Data transformed for analysis.)

Starking was consistently the firmest strain, although not significantly different from several others. Topred and Ryan Red were usually the softest, but it would be difficult to group the strains on the basis of firmness.

Soluble solids increased consistently through the three-week collection period (Table 12). Red Prince was always highest but only slightly above Ryan Red and Topred. The two spur-types, Starkrimson and Red Spur, were low in soluble solids, particularly at the earliest harvest date. By the third harvest date 
TABLE 12

Soluble solids of eight Delicious strains at harvest and after three storage periods, Block X, Kearneysville, 1969-70.

\begin{tabular}{|c|c|c|c|c|c|c|c|c|c|c|c|c|}
\hline \multirow[b]{2}{*}{ Strain } & \multicolumn{3}{|c|}{ At Harvest } & \multicolumn{3}{|c|}{60 Days } & \multicolumn{3}{|c|}{120 Days } & \multicolumn{3}{|c|}{180 Days } \\
\hline & $9 / 11$ & $9 / 18$ & $9 / 25$ & $9 / 11$ & $9 / 18$ & $9 / 25$ & $9 / 11$ & $9 / 18$ & $9 / 25$ & $9 / 11$ & $9 / 18$ & $9 / 25$ \\
\hline
\end{tabular}

\section{Soluble Solids - Per cent}

$\begin{array}{lllllllllllll}\vec{a} \quad \text { Red Prince } & 9.29 a^{1} & 9.69 a & 10.24 a & 11.39 a & 11.67 a & 11.29 a & 11.16 a & 11.61 a & 11.39 a & 10.98 a & 11.51 a & 11.32 a \\ \text { Ryan Red } & 9.20 a b & 9.42 a b & 9.99 a & 10.87 a b & 10.29 b & 11.31 a & 11.81 a & 11.31 a b & 10.98 a b & 10.99 a & 11.17 a b & 11.10 a b \\ \text { Topred } & 9.07 a b & 9.58 a b & 9.99 a & 10.50 a b & 10.12 b & 9.56 a & 10.28 a & 10.34 b c & 10.64 a b & 10.16 a b & 10.39 a b & 10.49 a b \\ \text { Starking } & 8.82 a b & 8.99 a b & 9.46 a & 10.13 b c & 10.38 b & 9.93 a & 10.55 a & 10.86 a b c & 10.44 a b & 10.36 a b & 10.71 a b & 10.92 a b \\ \text { Red Queen } & 8.69 a b c & 9.29 a b & 9.52 a & 9.96 b & 9.90 b & 10.22 a & 10.31 a & 10.19 b c & 10.37 a b & 10.05 a b & 9.99 b & 10.55 a b \\ \text { Starkrimson } & 8.65 a b c & 8.90 a b & 9.35 a & 9.96 b & 10.11 b & 10.46 a & 10.64 a & 10.29 b c & 10.58 a b & 10.57 a b & 10.60 a b & 10.74 a b \\ \text { Houser } & 8.61 b c & 9.19 a b & 9.33 a & 9.90 b & 10.30 b & 10.37 a & 10.65 a & 10.83 a b c & 10.42 a b & 10.55 a b & 10.74 a b & 10.72 a b \\ \text { Red Spur } & 8.21 c & 8.56 b & 9.33 a & 9.46 b & 10.29 b & 9.71 a & 10.15 a & 10.07 c & 10.12 b & 9.74 b & 10.28 a b & 9.98 b\end{array}$

${ }^{1}$ Means in a column followed by the same letter are not significantly different at the five per cent level. 
there was no significant differences between strains, although there was a considerable spread between the highest (Red Prince) and the lowest (Houser, Starkrimson, Red Spur). Variation between replicates reduced the possibility of detecting differences between strains.

In this experiment, storage behavior had to be judged primarily on the basis of changes in firmness since none of the strains developed significant amounts of scald or internal breakdown. For the fruit collected on the two earlier dates, there were only negligible changes in firmness after 60 days storage; indeed, several of the strains appeared to become slightly firmer. There were a few differences between strains collected on September 25. Topred and Red Prince were softening more rapidly than Red Spur, even though there was no significant difference in firmness between those three strains at harvest. All strains harvested on September 11 and stored 120 days softened at essentially the same rate, but delaying harvest for one week was associated with softer fruit and differences between strains. Bisbee and Red Spur softened less rapidly than the other strains. After 180 days, Houser and Topred from the earliest harvest had softened least, although they were significantly different only from Starking. The firmest strains were Bisbee, Red Spur, and Starking (Table 13).

Soluble solids increased during harvest. In general, the differences between strains that existed at harvest persisted in storage. There was some indication that soluble solids increased more rapidly in some strains after harvest than in others.

\section{Discussion}

The terms "mature" and "maturity" are frequently used by horticulturists and growers but there have been few attempts to define them. Lott (13) considers "mature" to be that stage of development reached by a fruit while it is still attached to the plant after which the edible (ripe) condition will be reached if that fruit is harvested. Applied to apples, maturity is the stage of development at which the fruit can be harvested and marketed to the final consumer in satisfactory condition. With Delicious apples, some period of storage is normally a component of marketing but this is not always true. A variable proportion of the Delicious crop is shipped in September and early October with essentially no storage. Fruit intended to be marketed under these conditions should be at a nearly edible stage when harvested. If some storage period is anticipated, it is not necessary that it be at this stage of harvest but it should be known that the fruit will become edible during storage and the other stages of the marketing sequence. Fruit should not be harvested beyond maturity for it will change to a non-edible (or at least non-saleable) condition before marketing is completed.

Like many other fruits, apples remain in the mature condition for only a limited time, which suggests that harvesting must be completed within an established period of time. The data presented here indicate that as harvest was 
TABLE 13

Firmness of eight Delicious strains at harvest and after three storage periods,

Block X, Kearneysville, 1969-70.

\begin{tabular}{|c|c|c|c|c|c|c|c|c|c|c|c|c|}
\hline \multirow[b]{2}{*}{ Strain } & \multicolumn{3}{|c|}{ At Harvest } & \multicolumn{3}{|c|}{60 Days } & \multicolumn{3}{|c|}{120 Days } & \multicolumn{3}{|c|}{180 Days } \\
\hline & $9 / 11$ & $9 / 18$ & $9 / 25$ & $9 / 11$ & $9 / 18$ & $9 / 25$ & $9 / 11$ & $9 / 18$ & $9 / 25$ & $9 / 11$ & $9 / 18$ & $9 / 25$ \\
\hline
\end{tabular}

\section{Firmness}

Starking

Starkrimson

Red Prince

Red Queen

Ryan Red

$\vec{\infty}$

Houser

Red Spur

Topred

\section{$19.09 a^{1} 18.69 a 20.57 a$} 18.90ab 17.94a 19.81ab 18.16abc 18.06a 19.25bc 18.02abc 18.08a 18.81bc 17.95abc $16.95 a$ 18.26c 17.63bc 17.67 a $18.35 c$ 17.48ab 17.90a 18.65c 17.06c 18.07a 18.41c 19.42a $19.27 a$

18.13a

$17.99 a$

$17.82 \mathrm{a}$

$18.71 \mathrm{a}$

$18.00 \mathrm{a}$

$17.82 \mathrm{a}$ 18.95ab 18.37a 19.17a 17.66ab 17.46abc 16.14b $17.19 \mathrm{bc} 16.27 \mathrm{~b}$ $16.02 \mathrm{c} \quad 15.56 \mathrm{~b}$ $17.42 \mathrm{abc} 16.77 \mathrm{~b}$ 18.03ab 17.46ab $17.60 \mathrm{abc} 16.03 \mathrm{~b}$ 16.74a 16.61bc 15.50abc 16.08b 15.95a $17.50 \mathrm{a} \quad 16.42 \mathrm{a}$ 16.67ab 16.20a 16.31 a $16.66 \mathrm{~b}$ 15.92a 15.28c 14.60bc 15.77a 15.32 bc $14.14 b c$ 15.59a 16.02bc 15.79ab 16.33a 15.56bc 17.06a $16.01 \mathrm{a} 15.53 \mathrm{bc} 14.18 \mathrm{bc}$
$15.67 \mathrm{~b} \quad 15.00 \mathrm{a}$ $16.12 \mathrm{~b} \quad 15.40 \mathrm{a}$ 16.62ab 15.84a $15.86 \mathrm{~b} \quad 15.45 \mathrm{a}$ $16.17 \mathrm{~b} \quad 14.92 \mathrm{a}$ 14.77ab $16.35 a$ $14.06 \mathrm{~b}$ $13.72 b$ $13.53 b$ $14.64 b$ $15.31 \mathrm{ab}$ $13.53 b$

\section{Fruit Diameter - Inches}

\begin{tabular}{|c|c|c|c|c|c|c|c|c|c|c|c|c|}
\hline opred & $2.82 a$ & $2.84 a$ & $2.89 a$ & $2.81 a$ & 2.78ab & $2.81 a$ & $2.84 a$ & $2.82 a$ & $2.88 a$ & $2.78 \mathrm{ab}$ & $2.86 a$ & $2.91 a$ \\
\hline Red Queen & $.81 a$ & $.82 a$ & $2.84 a$ & $2.74 a b$ & 2.79ab & $2.78 a$ & $2.77 a$ & $2.78 \mathrm{ab}$ & $2.82 a$ & $2.86 a$ & $2.82 \mathrm{abc}$ & $2.86 a b$ \\
\hline Red & $.81 a$ & $.84 a$ & $2.80 \mathrm{ab}$ & 2.79abc & $2.85 a$ & $77 a$ & $.79 a$ & $.80 a$ & $2.75 \mathrm{abc}$ & $2.80 \mathrm{ab}$ & 2.79abc & $85 a b$ \\
\hline & $.81 a$ & $2.84 a$ & & & & $2.82 a$ & $2.79 a$ & $76 a b$ & & & $a b$ & $4 a b$ \\
\hline & $.74 a$ & $.73 a$ & & & & & & & & & bc & $9 a b$ \\
\hline & 272 & $2.68 a$ & $72 \mathrm{~h}$ & $.66 b$ & & $.70 a b$ & $2.72 a$ & & $2.72 \mathrm{abc}$ & & & \\
\hline & $2.70 \mathrm{ab}$ & $2.70 a$ & & $2.65 b$ & & $2.70 \mathrm{ab}$ & $2.72 a$ & 2.69ab & $2.61 b c$ & $2.68 b c$ & $2.70 \mathrm{bcd}$ & $2.75 b c$ \\
\hline arking & $2.60 b$ & $2.67 a$ & $2.59 c$ & $2.53 d$ & $2.52 \mathrm{c}$ & $2.57 b$ & $2.55 b$ & $2.57 c$ & $2.59 c$ & $2.60 c$ & $2.61 d$ & $2.62 c$ \\
\hline
\end{tabular}

1 Means in a column followed by the same letter are not significantly different at the five per cent level. 
delayed, fruit softened more in storage, and in some cases softening was excessive. Since the Delicious proportion of the total crop is constantly increasing, the time required to harvest this one cultivar is also increasing. If all strains or budsports of Delicious mature uniformly the harvest labor force will have to be increased to insure harvest at maturity. On the other hand, if the strains reach maturity at different times, they could be harvested in sequence reflecting the maturity or best time to pick each strain. This would apply not only to the management of existing plantings but to the planning of new orchards.

Apple fruits show a good deal of variability among fruits and particularly between trees and this variability makes it difficult to detect differences at the conventional levels of confidence. As these studies progressed, it became apparent that differences between strains were not always statistically significant because not enough trees were being sampled. However, it would have been essentially impossible to increase the number of trees because collections were extended beyond the commercial harvest date. Fruit left on the trees would have been lost for an unacceptable economic loss in either private or university orchards. The conclusions from these studies are based on recurrent trends as well as demonstratable differences between strains in a given year and block.

The data on fruit firmness accumulated in these studies support earlier conclusions that this measurement is of little value as an indicator of maturity (15). Firmness did not change uniformly or progressively with time but appeared to be strongly influenced by environmental conditions. Increases in firmness were observed in 1964 after the second collection. There had been no significant rainfall prior to the September 17 collection; between that date and September $24,1.5$ inches of rain fell. This may have accounted for the increased firmness of fruit from Block $X$; however, this reasoning does not explain the firmness changes in Block $\mathrm{C}$. The firmness between the two blocks differed considerably, a further indication that growing conditions materially affect fruit firmness. It has been suggested that firmness at harvest may be some indication of how long fruit can be successfully stored, but with the unpredictable variations that occur within the period of accepted Delicious harvest (135-155 days after full bloom), it seems doubtful that harvest firmness data contributes much to harvest and storage management of Delicious.

In spite of the lack of published findings supporting the use of soluble solids as a guide to harvesting apples, it was elected to measure this parameter rather extensively. The method is simple and rapid enough to be used as a practical method. In almost every year there was a slow, constant increase in soluble solids up to about September 25 (140-145 days after full bloom). Strains which had been relatively high in soluble solids up to that time sometimes showed a slight decrease. This is interpreted to be an experimental or sampling error rather than a maturation or ripening process since its occurrence was sporadic. Red 
Prince, a strain that was consistently high in soluble solids, showed a decline only in 1964.

When all the data on soluble solids (Tables $1,2,4,6,9$ ) are examined certain trends are quite apparent. Certain strains consistently ranked high in soluble solids while others were always low. Although many orchardists were contacted, no trees of the original Delicious strain could be located. Starking and Richared, two of the earliest known budsports (and perhaps the most commonly planted strains of Delicious), had lower soluble solids than nearly all the other strains. Others of earlier known strains were sampled only in 1964, when sampling was restricted to a single tree. It appeared that Okanoma and Worthen No. 1 were low but the differences were too small for a definitive ranking of those strains. All of the other strains were budsports of either Richared or Starking, i.e., are "second generation" Delicious. Starkrimson (Bisbee), a spur-type strain that has been the most widely planted strain in the past 10 years or so, is a sport of Starking. It has been consistently low in soluble solids, particularly on the earlier collection dates.

As the 145-150 days after full bloom point was reached, the level of soluble solids in Starkrimson usually approached that in most other strains. Another spur-type, Red Spur, which is also derived from Starking as a whole tree sport, appeared to be relatively low in soluble solids in the two Kearneysville blocks sampled in 1964 and in Block $X$ in 1969. This strain has not fruited well and has not been planted extensively in commercial orchards, although it appears to have some potential. From these data, it might be suggested that the spur-types in general appear to mature more slowly than most other strains. On the other hand, Miller Spur, which was included in the 1968 collections, was very similar in soluble solids to two high-coloring standard tree strains.

In contrast to Starking, Richared, and Starkrimson, Red Prince contains high levels of soluble solids. The difference is most apparent about 135 days after full bloom. Red Prince is said to be a limb sport of common Delicious that develops a high degree of color in early September but does not become "over-colored." Houser, another standard type that colors early and intensely, has been relatively high in soluble solids in most cases but has not been as consistent or distinctive as Red Prince. Red Queen, which colors early but not as intensely as Red Prince, has tended to have high soluble solids at an early date. Strains with intermediate levels of soluble solids and horticultural characteristics that have justified or will justify their commercial adoption are Topred, Ryan Red, Red King, and Royal Red. Red King and Red Queen should probably be considered as obsolete for future commercial plantings, but a considerable number of trees have recently come into bearing.

The condition of fruit after periods of storage was determined in three different years. In no case were disorders such as rots, soft scald, and internal breakdown serious enough to be used as indicators of fruit quality and in only 
one year was storage scald severe; thus, storage behavior was judged largely by the firmness after cold storage plus one week at room temperature to simulate transport and shelf display at the retail level. Consideration has been given to both firmness itself and to changes in firmness after harvest.

There is no agreement on the most desirable firmness of Delicious apples at the time of consumption. Some years ago Haller gave the "prime eating" (9) of Delicious apples as 8-12 pounds, as measured with the Magness-Taylor pressure tester. Apparently, this conclusion was based on the softening of fruit stored in the then available cold storages. The losses in firmness were more rapid than observed in the present studies. It is possible that temperature control may have been less precise than can be achieved with more modern equipment and that softer apples were more acceptable than they would be now. In the present studies, it has been stipulated that Delicious fruit should have a firmness of 15-17 pounds when purchased by the consumer which would correspond to the "firm" class of Haller (9). A firmness of less than 12 pounds is considered here to make the fruit unacceptable. While these definitions of allowable firmness may not be universally accepted, they will provide a basis for the discussion of firmness changes during storage. Most attention will be directed toward the 1969-70 study since fruit was examined after more storage periods.

The data in Tables 7, 10, and 13 show that Delicious strains differ in the rate of softening in storage and that the changes are affected by harvest date. The "older" strains (Starking and Richared) and the spur types (Starkrimson and Red Spur) were consistently firmer and showed less change than the recently introduced, highly colored strains such as Red Prince, Topred, and Red Queen. Fruit harvested early (September 11, 1969, Tables 13 and 14) and held for only 60 days showed essentially no softening. The small increases represent sampling and testing errors. Similarly, fruit harvested on the middle date and stored for 60 days showed only slight decreases (apparent increases in two strains); however, some strains from the third harvest, September 25, 1969, had softened by as much as three pounds. Red Spur had softened significantly less than Topred and Red Prince.

As the harvest date was delayed, fruit was softer after any storage period and the simulated shelf period. This was most clearly demonstrated in the 1969-70 study (Tables 13 and 14), but also holds true for the 1968-69 study (Tables 7-11). It is also obvious that there are considerable differences between years and source of fruit. There was a difference in firmness after storage of Starkrimson, Red Prince, and Red Queen from two orchards sampled in 1968, which differed in altitude, soil type, and rootstock. In that year all of the fruit was softer than considered desirable but within Haller's limits (9).

In 1969, only Topred was approaching an acceptable firmness for immediate marketing on September 11 (130 days after full bloom) although commercial harvest of fruit with sufficient color to satisfy grade requirements 
was in progress at that time. After that date firmness did not change appreciably. At that time, marketing pressures were forcing the marketing of fruit hardly ready for consumption. The same appeared to be true in 1964 in Block $X$, although the fruit from Block $C$ should have been acceptable as early as September 8 if firmness were the only consideration; however, fruit from the same block was overly firm as late as September 26 in 1967 (Table 3). It has been traditional to market as much fruit as possible directly in the fall because of favorable prices and to avoid storage costs. Color has been and probably will continue to be the principal factor in determining when fruit is harvested to satisfy the "early" market. Characteristics such as firmness, sugar concentration, and starchiness are rarely considered. Hopefully, the producer and shipper would at least satisfy themselves that fruit has reasonably good eating quality before it is offered to consumers.

In the 1969-70 season, no strain harvested on September 11 and stored 60 days had softened to the established range and only Ryan Red harvested on September 18 was within the range. Several strains were with in the acceptable range when harvested on September 25 and stored for 60 days.

In West Virginia, January 15 to February 1, about 120 days after harvest, represents about the end of the storage operation for Delicious apples. Quantities have been reduced to a small fraction of the total crop and it is about then that quality declines because of scald, microbial decay, and internal breakdown. Storage for longer periods occurs occasionally because of very large crops locally or nationally. With the increases in Delicious plantings and production mentioned previously, longer storage seasons will probably become more common; thus, $\mathbf{1 2 0}$ days of stroage represents a critical time at present with longer periods becoming more important in the future.

After 120 days of storage in the $1969-70$ season, all strains were within the acceptable range of 15-17 pounds except for a few examples of over softness, viz., Ryan Red, Red Prince, and Topred harvested on September 25 (144 days after full bloom). Starkrimson was perhaps still too firm. Table 14 shows that some strains softened rapidly in the 60-120-day interval, specifically Starking, Red Queen, Red Prince, Ryan Red, and Topred.

Fruit harvested 130 days after full bloom and stored 180 days was within the acceptable firmness range. Topred harvested later had become too soft. Several other strains were too soft when harvested 137 days after full bloom (September 18) and apparently should not have been held much longer than 120 days. Starkrimson and Red Spur were in satisfactory condition at the end of the longest storage period.

It should be possible to substantially reduce storage losses if there were a method or system available which would predict how fruit was going to behave in storage. Data collected in this study and from other sources show that neither firmness nor titratable acidity at harvest show any distinctive pattern that 
TABLE 14

Changes in firmness of eight Delicious strains during storage at $0^{\circ} \mathrm{C}$ plus 7 days at $20^{\circ} \mathrm{C}$, Block X, Kearneysville, 1969-70.

\begin{tabular}{|c|c|c|c|c|c|c|c|c|c|}
\hline \multirow[b]{2}{*}{ Strain } & \multicolumn{3}{|c|}{60 Days } & \multicolumn{3}{|c|}{120 Days } & \multicolumn{3}{|c|}{180 Days } \\
\hline & $9 / 11$ & $9 / 18$ & $9 / 25$ & $9 / 11$ & $9 / 18$ & $9 / 25$ & $9 / 11$ & $9 / 18$ & $9 / 25$ \\
\hline \multicolumn{10}{|c|}{ Changes in Firmness } \\
\hline Starking & $+0.33 a^{1,2}$ & $0.55 a$ & $2.20 \mathrm{ab}$ & $2.35 a$ & $2.08 a$ & $5.07 a$ & $3.01 \mathrm{a}$ & $3.94 a$ & $5.80 \mathrm{a}$ \\
\hline Red Queen & $0.03 a$ & $0.89 a$ & $2.54 a b$ & $2.10 a$ & $2.80 \mathrm{a}$ & $4.21 \mathrm{a}$ & $2.27 a b$ & $3.09 a$ & $5.08 \mathrm{ab}$ \\
\hline Red Prince & $0.03 a$ & $0.60 a$ & $3.11 a$ & $1.85 a$ & $1.40 \mathrm{ab}$ & $5.22 \mathrm{a}$ & $1.49 \mathrm{ab}$ & $1.87 a$ & 5.19ab \\
\hline Ryan Red & $0.13 a$ & $0.93 a$ & $2.70 a b$ & $2.18 a$ & $1.63 a b$ & $4.61 \mathrm{a}$ & $1.83 a b$ & $1.55 a$ & $4.83 a b$ \\
\hline Red Spur & $+0.52 a$ & $+0.13 a$ & $.27 b$ & $1.15 a$ & $2.34 a$ & $1.45 b$ & $1.62 \mathrm{ab}$ & $2.45 a$ & $2.71 b$ \\
\hline Starkrimson & $+0.37 a$ & $+1.23 a$ & $2.15 a b$ & $1.88 a$ & $+1.03 b$ & 2.83ab & $1.40 \mathrm{ab}$ & $1.46 a$ & 3.46ab \\
\hline Houser & $+1.08 \mathrm{a}$ & $0.25 a$ & 1.58ab & $2.05 a$ & 1.65ab & $2.56 a b$ & $1.01 b$ & $1.83 a$ & $3.70 a b$ \\
\hline Topred & $+0.76 a$ & $0.47 a$ & $3.29 a$ & $1.05 a$ & $2.54 a$ & $4.59 a$ & $0.89 b$ & $3.15 a$ & $5.12 a b$ \\
\hline
\end{tabular}

${ }^{1}$ Changes are decreases or negative except when indicated as increase or positive.

2 Means in a column followed by the same letter are not significantly different at the five per cent level. 
corresponds to maturation. When all data ( 4 years) are viewed together, there is a clear suggestion that soluble solids progressively increase with time and that there are small but distinct and repetitive differences among Red Delicious strains. Soluble solids were found to be significantly correlated with firmness after storage. The frequency of significant correlations increased with length of storage period. Study of the data also indicated that when soluble solids increased above 10.3-10.5 per cent, the fruit was excessively soft after extended cold storage (greater than 120 days). In the 1969-70 season no soluble solid measurements greater than 10.25 per cent were recorded (Table 12) and there were very few examples of excessively soft fruit after storage. On the basis of soluble solids, it is clear that the harvests on September 11 and 18, 1969, were too early for storage. Soluble solids at harvest and firmness after storage were not significantly correlated ( $r=-0.157,-0.159)$. By September 25 , when soluble solids of all strains were at least above 9.0 per cent, $r$ equaled 0.686 , significant at the 5 per cent level. In the 1968-69 season, correlations were high and always significant when soluble solids were 9.5-11.0 per cent. Outside this range, correlations were a good deal lower.

It seems warranted to conclude that soluble solids may be used as a guide to the harvest of Red Delicious apples and that each strain must be handled individually. Color is not a satisfactory guide to harvesting, particularly for storage. At the present time, $\mathbf{1 0 . 5}$ per cent soluble solids may be taken as a critical value. When harvesting for immediate movement or short time storage, factors such as firmness, acidity, and starchiness must be considered. Soluble solids should be monitored closely beginning about 130 days after full bloom. Adherence to this system should promote more orderly and profitable growing of Red Delicious apples. 